\title{
Mechanical properties of cellulose nanofiber (CNF) reinforced polylactic acid (PLA) prepared by twin screw extrusion
}

\begin{abstract}
The aim of this study was to develop cellulose nanofiber (CNF) reinforced polylactic acid (PLA) by twin screw extrusion. Nanocomposites were prepared by premixing a master batch with high concentration of CNFs in PLA and diluting to final concentrations (1, 3, 5 wt.\%) during the extrusion. Morphology, mechanical and dynamic mechanical properties (DMA) were studied theoretically and experimentally to see how different CNF concentrations affected the compositesôproperties. The tensile modulus and strength increased from $2.9 \mathrm{GPa}$ to $3.6 \mathrm{GPa}$ and from $58 \mathrm{MPa}$ to $71 \mathrm{MPa}$, respectively, for nanocomposites with $5 \mathrm{wt}$.\% CNF. The DMA results were also positive; the storage modulus increased for all nanocomposites compared to PLA; being more significant in the high temperature region $\left(70{ }^{\circ} \mathrm{C}\right)$. The addition of nanofibers shifted the tan delta peak towards higher temperatures. The tan delta peak of the PLA shifted from $70{ }^{\circ} \mathrm{C}$ to $76{ }^{\circ} \mathrm{C}$ for composites with 5 wt. $\% \mathrm{CNF}$.
\end{abstract}

Keyword: A. Nanocomposites; B. Mechanical properties; C. Modeling; D. Dynamic mechanical thermal analysis; E. Extrusion 